\title{
Relationship between blood eosinophils, clinical characteristics, and mortality in patients with COPD
}

This article was published in the following Dove Press journal:

International Journal of COPD

20 June 2017

Number of times this article has been viewed

\section{Maeva Zysman,' Gaëtan Deslee, ${ }^{2}$ Denis Caillaud, ${ }^{3}$ Pascal Chanez, ${ }^{4}$ Roger Escamilla, ${ }^{5}$ Isabelle Court-Fortune, ${ }^{6}$ Pascale Nesme-Meyer, ${ }^{7}$ Thierry Perez, ${ }^{8}$ Jean-Louis Paillasseur, ${ }^{9}$ Christophe Pinet, ${ }^{10}$ Gilles Jebrak," Nicolas Roche, ${ }^{12, *}$ Pierre-Régis Burgel ${ }^{12, *}$ \\ On behalf of the Initiatives BPCO (broncho- pneumopathie chronique obstructive) Scientific Committee and Investigators}

'Pulmonary Dpt, Nancy, Inserm U955, team 04, Créteil, France; ${ }^{2}$ Pulmonary Dpt, Maison Blanche University Hospital, INSERM U903, Reims, France; ${ }^{3}$ Pulmonary Dpt, Gabriel Montpied University Hospital, Auvergne University, Clermont-Ferrand, France; ${ }^{4}$ Pulmonary Dpt, APHM, INSERM UI077, CNRS UMR 7733 Aix Marseille Université, Marseille, France; ${ }^{5}$ Pulmonary Dpt, Larrey University Hospital, Toulouse, France; 'Pulmonary Dpt, University Hospital, Saint-Etienne, France; ${ }^{7}$ Pulmonary Dpt, La Croix Rousse University Hospital, Lyon, France; ${ }^{8} \mathrm{Clinique}$ des Maladies Respiratoires, Albert Calmette University Hospital, Lille, France; ${ }^{9} \mathrm{EFFI}-\mathrm{STAT}$, Paris, France; ${ }^{10}$ Service de pneumologie, polyclinique Les Fleurs, Ollioules, France; "'Pulmonary Dpt, Bichat Hospital, AP-HP, Paris, France; ${ }^{12}$ Respiratory and Intensive Care Medicine Dpt, Cochin Hospital, AP-HP and Paris Descartes University (EA25II), Sorbonne Paris Cité, Paris, France

*These authors contributed equally to this work

Correspondence: Maéva Zysman Unite Inserm U955, Equipe 4, Faculté de Médecine de Créteil, $\mathrm{CHU} \mathrm{H.} \mathrm{Mondor,} 8$ rue du général Sarrail, 94000 Creteil, France Tel +33617258793

Fax +33 I5 84I 2260 Email maeva.zysman@inserm.fr
Abstract: In patients with COPD, there is controversy regarding the association of blood eosinophil (Eos) levels with 1) exacerbation frequency and 2) the effect of inhaled corticosteroids for prevention of exacerbations. To determine whether Eos define subgroups of patients exhibiting attributes of COPD clinical phenotypes, we compared clinical features and mortality rates in COPD patients from the Initiatives BPCO French cohort categorized using different thresholds of blood Eos levels. The following data were collected at inclusion: medical and smoking history, occupational exposures, dyspnea, cough and sputum production, exacerbations in the previous year, history of allergy and asthma, nasal symptoms, body mass index, St George Respiratory Questionnaire (SGRQ) total score, post-bronchodilator spirometry, comorbidities, and medications. Three-year survival between groups was compared using Kaplan-Meier analysis. Three sets of analyses were performed to compare patients with $\geq 2 \%$ versus $<2 \%$, $\geq 3 \%$ versus $<3 \%$, and $\geq 4 \%$ versus $<4 \%$ Eos. Eos was available in 458 patients (mean age: 62 years, $72 \%$ male, mean forced expiratory volume in 1 second: $51 \%$ pred), including 235 patients with Eos $\geq 2 \%$ (49\%), 149 with Eos $\geq 3 \%$ (33\%), and 90 with Eos $\geq 4 \%$ (20\%). For all cutoffs, there was no difference between Eos+ and Eos- groups in univariate analyses except for diabetes and SGRQ score (more frequent and more impaired, respectively, in lower Eos categories). In particular, there was no difference in exacerbation rate, history of asthma, or three-year survival. In conclusion, regardless of the cutoff, Eos+ COPD patients exhibited no specific characteristic in terms of symptoms, lung function, exacerbation rate, and prognosis. These findings suggest that the association of higher Eos with exacerbations reported in previous studies could be population specific, which does not support generalizing the use of Eos as a biomarker for COPD phenotyping.

Keywords: COPD, eosinophils, survival, exacerbations, quality of life

\section{Introduction}

Several studies have been conducted to better understand the heterogeneity of patients with COPD and to identify different phenotypes and endotypes. More specifically, identifying clinically relevant phenotypes with specific responses to treatments is an important goal for current and future research, in order to allow proper treatment personalization based on the predicted benefit/risk ratio of each available drug class in each individual patient. ${ }^{1}$ Biomarkers represent an important avenue of research in this area. Several studies suggest that, in patients with COPD, high sputum and blood eosinophil (Eos) counts are associated with specific clinical phenotypes defined by 1) more frequent exacerbations and 2) better response to inhaled corticosteroids (ICS) for exacerbation prevention. ${ }^{2-6}$ Additionally, ICS therapy has been suggested to reduce 
the rate of decline in forced expiratory volume in 1 second $\left(\mathrm{FEV}_{1}\right)$ in patients with high blood Eos counts. ${ }^{7}$ However, in that study, higher Eos was associated with a decreased preventive effect of ICS on exacerbation risk. Contradictory data have also been found regarding the yield of Eos to predict outcomes and response to oral corticosteroids during acute exacerbations, a relation being shown in some, ${ }^{8,9}$ but not all, studies. ${ }^{10}$ Data on the relations between Eos count and longterm survival in COPD patients are scarce. ${ }^{11}$

To determine whether Eos define subgroups of patients exhibiting attributes of COPD clinical phenotypes, possible associations between Eos and clinical characteristics and prognosis in COPD patients were further explored in a French cohort of subjects with spirometry-confirmed COPD.

\section{Methods}

Data from the Initiatives BPCO French cohort of smokers and ex-smokers ( $>10$ pack-years), aged $>40$ years with spirometry-confirmed COPD $(n=1,128$ when data were extracted), were analyzed. As previously described, ${ }^{12}$ patients from this cohort are recruited by respiratory physicians from tertiary care university hospital centers. A current main diagnosis of asthma is an exclusion criterion, but a past history of asthma in childhood or early adulthood is allowed. Patients were divided into Eos+ and Eos- groups based on blood Eos level, using several thresholds ( $\geq$ and $<2 \%, 3 \%$, and $4 \%$ ). Differences in mortality rates and clinical characteristics were assessed using chi-square tests or Fisher's exact tests, as appropriate, for discrete variables, and Wilcoxon or Kruskal-Wallis tests for quantitative variables. The following data collected at inclusion were compared between groups: medical and smoking history, occupational exposures, dyspnea, cough and sputum production, exacerbations in the previous year, history of allergy and asthma, nasal symptoms, body mass index, St George Respiratory Questionnaire (SGRQ) total score, post-bronchodilator spirometry, physician-diagnosed comorbidities, and medications. Vital status was available for all patients. Overall survival was assessed using the Kaplan-Meier method.

\section{Ethics approval}

The study was approved by the Ethics Committee of Versailles, France (number: 04-479) for the protection of human beings involved in biomedical research. All patients provided written consent.

\section{Results}

Blood Eos count was available in 458 patients (mean age: 62 years, $72 \%$ male, mean $\mathrm{FEV}_{1}: 51 \%$ pred), who did not differ from those with no Eos count in terms of clinical and lung function characteristics or outcomes (not shown). The median (interquartile range [IQR]) Eos level was $1.90(0.9-3.4) \%$. The population comprised 223 patients with Eos $\geq 2 \%$ (49\%), 149 with Eos $\geq 3 \%$ (33\%), and 90 with Eos $\geq 4 \%$ (20\%). Table 1 presents comparisons between Eos $+(n=223 ; 49 \%)$ and Eos $-(n=235 ; 51 \%)$ patients using the $2 \%$ threshold. Median follow-up was $48(33 ; 104)$ months and was not different between Eos+ and Eos- patients $(P=0.64)$. All-cause mortality rate was $13 \%$ in Eos+ versus $17 \%$ in Eos- $(P=0.23)$, and there was no significant difference in terms of 3-year survival (Figure 1). Diabetes was less prevalent in Eos+ patients ( $8 \%$ vs $17 \%$ in Eos,$- P=0.01$ ). Further, SGRQ total score was lower in Eos+ patients (median, 40 units vs 48 units in Eos-, $P=0.007$ ), reflecting better quality of life. There was no other difference between Eos+ and Eos-participants regarding clinical characteristics, lung function, comorbidities, and treatments. Eos+ patients were not more prone to exacerbations (median, 1 exacerbation/ patient/year in both groups, $P=0.247$ ), which could not be explained by a more frequent use of ICS or history of asthma ( $14 \%$ vs $13.5 \%$ in Eos-, $P=0.86$ ) (Table 1). All analyses were repeated using thresholds of $3 \%$ and $4 \%$ to categorize patients, which provided comparable results (not shown). Even when the population was divided into four groups $<2 \%$ (235 patients), $\geq 2 \%$, and $<3 \%$ (74 patients), $\geq 3 \%$ and $<4 \%$ (59 patients), and $\geq 4 \%$ (90 patients), the only significant differences regarded SGRQ total score and diabetes (Table 2). There was also no significant difference in terms of 3-year survival, among these four groups (Figure 2).

\section{Discussion}

The main finding from this real-life cohort study is the lack of noticeable difference in prognosis and in most clinical and lung function features between COPD patients with higher versus lower blood Eos levels, for all tested thresholds of Eos $(2 \%, 3 \%$, and $4 \%)$.

In this population, half of the participants had Eos $\geq 2 \%$, which is comparable to what was observed, for example, in the WISDOM study ${ }^{13}$ but less than in several other studies of patients with COPD identified from the general population ${ }^{14}$ or clinical trials. This finding underscores the heterogeneity of COPD patients recruited in different cohorts. Although patients with a current primary diagnosis of asthma were not recruited in the present cohort, patients with a past history of asthma represented $13 \%$ of the population but did not exhibit higher Eos levels (median: 1.9, IQR 0.9-3.4 in both patients with and without associated asthma). In addition, their clinical characteristics and outcomes were similar to 
Table I Characteristics of 458 patients with COPD according to the $2 \%$ blood eosinophil cutoff

\begin{tabular}{|c|c|c|c|c|c|}
\hline \multirow[t]{2}{*}{ Variables } & \multicolumn{2}{|l|}{ Eos $\geq 2 \%(N=223)$} & \multicolumn{2}{|l|}{ Eos $<2 \%(N=235)$} & \multirow[t]{2}{*}{$P$-values } \\
\hline & & Missing values & & Missing values & \\
\hline Sex, M/F & $72.6 \%(162) / 27.4 \%(6 I)$ & 0 & $71.5 \%(168) / 28.5 \%(67)$ & 0 & 0.783 \\
\hline Age, years & $62(55-70)$ & 0 & $62(55-70)$ & 0 & 0.715 \\
\hline BMI $\left(\mathrm{kg} / \mathrm{m}^{2}\right)$ & $25.3(21.9-29.4)$ & 0 & $24.2(21.2-28.4)$ & 0 & 0.093 \\
\hline Obesity $(\mathrm{BMI}>30$ kg/m²) & $22.0 \%(49)$ & 0 & $18.3 \%(43)$ & 0 & 0.326 \\
\hline Smoking habits & & 7 & & 5 & 0.542 \\
\hline Former smoker & $67.6 \%(146)$ & & $62.6 \%(144)$ & & \\
\hline Current smoker & $29.6 \%(64)$ & & $34.3 \%(79)$ & & \\
\hline Never smoker & $2.8 \%(6)$ & & $3.0 \%(7)$ & & \\
\hline Cumulative smoking (pack-years) & $36.0(24.0-54.0)$ & 22 & $37.1(22.5-52.5)$ & 25 & 0.704 \\
\hline History of asthma & $13.5 \%(30)$ & 15 & $14.0 \%(33)$ & 13 & 0.855 \\
\hline Hay fever & $9.9 \%(22)$ & 0 & $12.3 \%(29)$ & 0 & 0.400 \\
\hline Eczema & $7.6 \%(17)$ & 0 & $8.1 \%(19)$ & 0 & 0.854 \\
\hline Rhinitis/sinusitis & $17.5 \%(39)$ & 0 & $20.4 \%(48)$ & 0 & 0.423 \\
\hline Occupational exposures & $27.8 \%(62)$ & 0 & $32.3 \%(76)$ & 0 & 0.290 \\
\hline Chronic cough and sputum production & $65.9 \%(147)$ & 14 & $71.9 \%(169)$ & 0 & 0.166 \\
\hline Exacerbation rate (per patient-year) & $1.0(0.0-2.0)$ & 5 & $1.0(0.0-3.0)$ & 7 & 0.247 \\
\hline Severe (hospitalized) exacerbation & $0.0(0.0-0.0)$ & 5 & $0.0(0.0-1.0)$ & 7 & 0.174 \\
\hline \multicolumn{6}{|l|}{ rate (per patient-year) } \\
\hline mMRC dyspnea grade & $2(I-2)$ & 18 & $2(I-3)$ & 21 & 0.211 \\
\hline Ischemic heart disease & $11.2 \%(25)$ & 0 & $11.5 \%(27)$ & 0 & 0.925 \\
\hline Chronic heart failure & $11.2 \%(25)$ & 0 & $13.2 \%(3 \mid)$ & 0 & 0.518 \\
\hline Diabetes mellitus & $8.1 \%(18)$ & 0 & $16.6 \%(39)$ & 0 & 0.006 \\
\hline SGRQ total score & $40(30-56)$ & 33 & $48(32-63)$ & 30 & 0.007 \\
\hline $\mathrm{FEV}_{1} \%$ predicted & $52(37-68)$ & 0 & $51(34-70)$ & 0 & 0.658 \\
\hline ICS outside fixed-dose combinations & $21.5 \%(48)$ & 5 & $23.0 \%(54)$ & 10 & 0.709 \\
\hline ICS + long-acting beta-agonist & $41.7 \%(93)$ & 5 & $36.2 \%(85)$ & 10 & 0.225 \\
\hline Long-acting antimuscarinic agents & $30.5 \%(68)$ & 5 & $34.0 \%(80)$ & 10 & 0.299 \\
\hline Oral steroids & $5.1 \%(12)$ & 5 & $2.2 \%(5)$ & 10 & 0.120 \\
\hline Follow-up duration (months) & $45(33-100)$ & I & $51(29-107)$ & I & $0.64 I$ \\
\hline Death rate & $13.0 \%(29)$ & I & $17.0 \%(40)$ & I & 0.230 \\
\hline
\end{tabular}

Notes: Data are expressed as the median (quartile I-quartile 3) or \% (n). Data were assessed using chi-square tests or Fisher's exact tests, as appropriate, for discrete variables, and Wilcoxon tests for quantitative variables.

Abbreviations: BMI, body mass index; Eos, eosinophils; FEV, forced expiratory volume in I second; ICS, inhaled corticosteroids; mMRC, modified Medical Research Council; SGRQ, St George Respiratory Questionnaire.

that of other patients..$^{15}$ This may relate to a tendency of investigators to refrain from including patients with higher Eos counts (Eos was $<4 \%$ in $>80 \%$ of the population) in COPD cohorts, even when this is not an exclusion criterion.

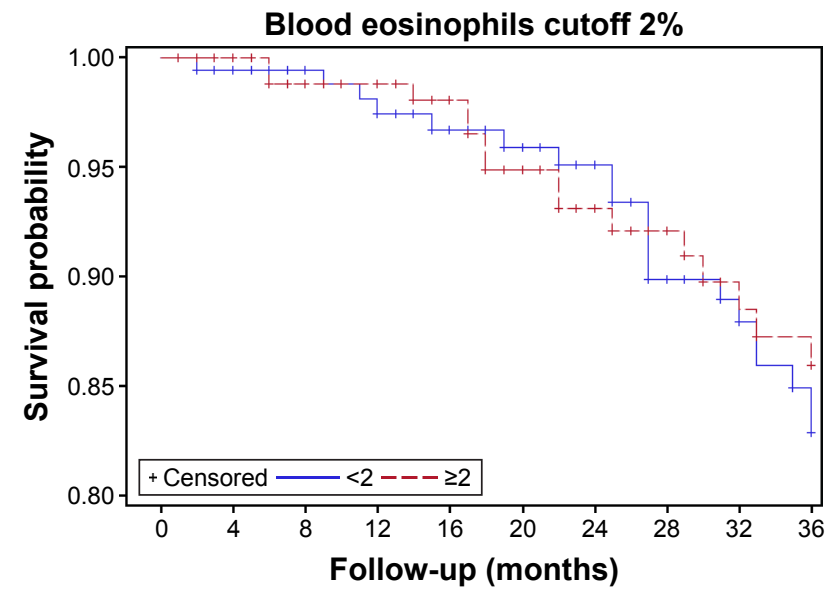

Figure I Kaplan-Meier analysis for comparison of survival between COPD patients with high versus low eosinophils using the $2 \%$ blood eosinophil cutoff.
A similar hypothesis may be proposed to explain why Eos (threshold: 2\%) did not predict response to ICS in the Flame trial, ${ }^{10}$ where patients with blood Eos $>600 / \mathrm{mm}^{3}$ could not be recruited, while higher Eos was significantly associated with response to ICS in several post hoc analyses from previous trials $^{3,5,6}$ Discrepancies between study results may also relate to differences in COPD severity: for instance, our population had less severe airflow obstruction than patients from the Evaluation of COPD Longitudinally to Identify Predictive Surrogate Endpoints (ECLIPSE) cohort (mean $\mathrm{FEV}_{1}: 51 \%$ pred vs $44 \%$ pred). Conversely, patients from the Copenhagen City Heart Study clinical COPD cohort $(n=203)^{4}$ had similar $\mathrm{FEV}_{1}$ levels compared to our population. In this later population, there was a higher rate of severe exacerbations in patients with an Eos level $\geq 2 \%$, while this relation was surprisingly in the opposite direction for moderate exacerbations. ${ }^{4}$ In our population, neither moderate nor severe (ie, hospitalized) exacerbations were different between Eos+ and Eos-groups. Another point to consider when interpreting study results is that, in many cases, Eos count was measured 
Table 2 Characteristics of 458 patients with COPD according to four different blood eosinophil cutoffs: $<2 \%, \geq 2 \%$ and $<3 \%, \geq 3 \%$ and $<4 \%$, and $\geq 4 \%$

\begin{tabular}{|c|c|c|c|c|c|c|c|c|c|}
\hline \multirow[t]{2}{*}{ Variables } & \multicolumn{2}{|c|}{$<\mathbf{2} \%(\mathrm{~N}=\mathbf{2 3 5})$} & \multicolumn{2}{|c|}{$\begin{array}{l}\geq \mathbf{2} \% \text { and }<\mathbf{3} \% \\
(\mathbf{N}=\mathbf{7 4})\end{array}$} & \multicolumn{2}{|c|}{$\begin{array}{l}\geq \mathbf{3} \% \text { and }<\mathbf{4} \% \\
(\mathbf{N}=\mathbf{5 9})\end{array}$} & \multicolumn{2}{|c|}{$\geq 4 \%(\mathrm{~N}=90)$} & \multirow[t]{2}{*}{$P$-values } \\
\hline & & $\begin{array}{l}\text { Missing } \\
\text { values }\end{array}$ & & $\begin{array}{l}\text { Missing } \\
\text { values }\end{array}$ & & $\begin{array}{l}\text { Missing } \\
\text { values }\end{array}$ & & $\begin{array}{l}\text { Missing } \\
\text { values }\end{array}$ & \\
\hline \multirow[t]{2}{*}{ Sex, M/F } & $71.5 \%(168) /$ & 0 & $73.0 \%(54) /$ & 0 & $71.2 \%(42) /$ & 0 & $73.3 \%(66) /$ & 0 & 0.983 \\
\hline & $28.5 \%(67)$ & & $27.0 \%(20)$ & & $28.8 \%(17)$ & & $26.7 \%(24)$ & & \\
\hline Age, years & $62(55-70)$ & 0 & 61 (55-69) & 0 & 61 (54-69) & 0 & $63(56-72)$ & 0 & 0.712 \\
\hline BMI $\left(\mathrm{kg} / \mathrm{m}^{2}\right)$ & $24(2 I-28)$ & 0 & $25(23-3 I)$ & 0 & $\begin{array}{l}\text { Min } 17.26 \\
(22-29)\end{array}$ & 0 & $24(20-29)$ & 0 & 0.074 \\
\hline Obesity (BMI > 30 kg/m²) & $18.3 \%(43)$ & 0 & $27.0 \%(20)$ & 0 & $22.0 \%(13)$ & 0 & $17.8 \%(16)$ & 0 & 0.372 \\
\hline Smoking habits & & 5 & & 1 & & 4 & & 2 & 0.484 \\
\hline Former smoker & $62.6 \%(144)$ & & $72.6 \%(53)$ & & $61.8 \%(34)$ & & 67.0\% (59) & & \\
\hline Current smoker & $34.3 \%(79)$ & & $27.4 \%(20)$ & & $32.7 \%(18)$ & & $29.5 \%(26)$ & & \\
\hline Never smoker & $3.0 \%(7)$ & & $0.0 \%(0)$ & & $5.5 \%(3)$ & & $3.4 \%(3)$ & & \\
\hline \multirow[t]{2}{*}{ Cumulative smoking (pack-years) } & 37.1 & 25 & 38.0 & 5 & 39.0 & 6 & 31.0 & 11 & 0.379 \\
\hline & $(22.5-52.5)$ & & $(24.0-50.0)$ & & $(28.5-55.0)$ & & $(20.0-55.5)$ & & \\
\hline History of asthma & $14.0 \%(33)$ & 0 & $13.5 \%(10)$ & 0 & $11.9 \%(7)$ & 0 & $14.4 \%(13)$ & 0 & 0.972 \\
\hline Hay fever & $12.3 \%(29)$ & 0 & $8.1 \%(6)$ & 0 & $5.1 \%(3)$ & 0 & $14.4 \%(13)$ & 0 & 0.240 \\
\hline Eczema & $8.1 \%(19)$ & 0 & $4.1 \%(3)$ & 0 & $8.5 \%(5)$ & 0 & $10.0 \%(9)$ & 0 & 0.531 \\
\hline Rhinitis/sinusitis & $20.4 \%(48)$ & 0 & $17.6 \%(13)$ & 0 & $18.6 \%(11)$ & 0 & $16.7 \%(15)$ & 0 & 0.866 \\
\hline Occupational exposures & $32.3 \%(76)$ & 0 & $23.0 \%(17)$ & 0 & $22.0 \%(13)$ & 0 & $35.6 \%(32)$ & 0 & 0.142 \\
\hline Chronic cough and sputum production & $71.9 \%(169)$ & 0 & $59.5 \%(44)$ & 0 & $62.7 \%(37)$ & 0 & $73.3 \%(66)$ & 0 & 0.113 \\
\hline Exacerbation rate (per patient-year) & I & 7 & I & 1 & 1 & 2 & 1 & 2 & 0.581 \\
\hline Severe (hospitalized) exacerbation & 0.5 & 7 & 0.3 & 1 & 0.5 & 2 & 0.4 & 2 & 0.195 \\
\hline \multicolumn{10}{|l|}{ rate (per patient-year) } \\
\hline mMRC dyspnea grade & 2 & 21 & 2 & 7 & 2 & 5 & 2 & 6 & 0.665 \\
\hline Ischemic heart disease & II.5 (27) & 0 & $6.8 \%(5)$ & 0 & $13.6 \%(8)$ & 0 & $13.3 \%(12)$ & 0 & 0.533 \\
\hline Chronic heart failure & $\mid 3.2 \%(3 \mid)$ & 0 & $12.2 \%(9)$ & 0 & $8.5 \%(5)$ & 0 & $12.2 \%(11)$ & 0 & 0.807 \\
\hline Diabetes mellitus & $16.6 \%(39)$ & 0 & $12.2 \%(9)$ & 0 & $5.1 \%(3)$ & 0 & $6.7 \%(6)$ & 0 & 0.024 \\
\hline SGRQ total score & 48 & 30 & 43 & 16 & 40 & 9 & 36 & 8 & 0.047 \\
\hline $\mathrm{FEV}$, \% predicted & 51 & 0 & 53 & 0 & 54 & 0 & 51 & 0 & 0.878 \\
\hline ICS outside fixed-dose combinations & $23.0 \%(54)$ & 0 & $23.0 \%(17)$ & 0 & $15.3 \%(9)$ & 0 & $24.4 \%(22)$ & 0 & 0.570 \\
\hline ICS + long-acting beta-agonist & $36.2 \%(85)$ & 0 & $43.2 \%(32)$ & 0 & $44.1 \%(26)$ & 0 & $38.9 \%(35)$ & 0 & 0.575 \\
\hline Long-acting antimuscarinic agents & $34.0 \%(80)$ & 0 & $28.4 \%(21)$ & 0 & $35.6 \%(21)$ & 0 & $28.9 \%(26)$ & 0 & 0.655 \\
\hline Oral steroids & $5.1 \%(12)$ & 0 & $2.7 \%(2)$ & 0 & $3.4 \%(2)$ & 0 & $1.1 \%(1)$ & 0 & 0.408 \\
\hline Follow-up duration (months) & 51 & 0 & 46 & 0 & 53 & 0 & 45 & 0 & 0.885 \\
\hline Death rate & I7.I (40) & I & $17.6 \%(13)$ & 0 & $8.5 \%(5)$ & 0 & $12.4 \%(11)$ & 1 & 0.306 \\
\hline
\end{tabular}

Notes: Data are expressed as the median (quartile I-quartile 3) or \% (n). Data were assessed using chi-square tests or Fisher's exact tests, as appropriate, for discrete variables, and Wilcoxon tests for quantitative variables.

Abbreviations: BMI, body mass index; Eos, eosinophils; $\mathrm{FEV}_{1}$, forced expiratory volume in I second; ICS, inhaled corticosteroids; mMRC, modified Medical Research Council; SGRQ, St George Respiratory Questionnaire.

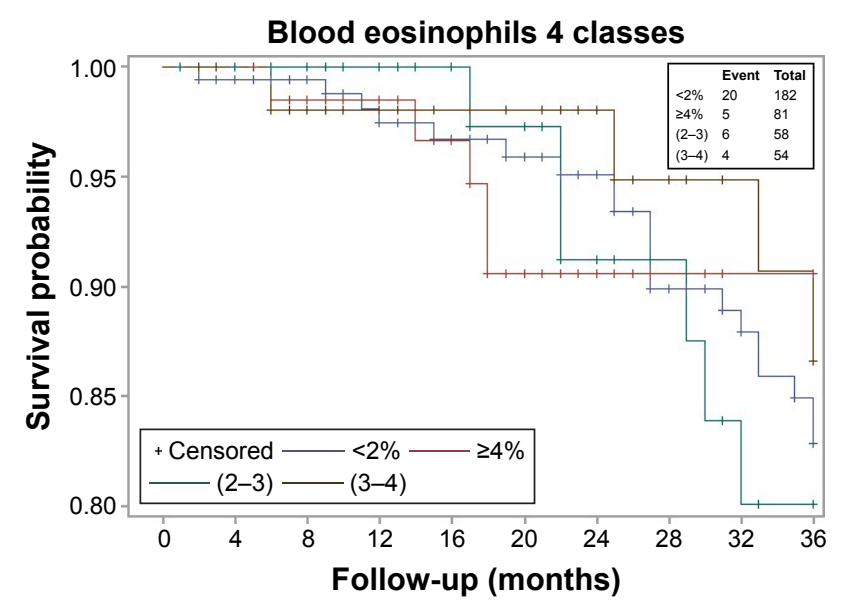

Figure 2 Kaplan-Meier analysis for comparison of survival between COPD patients with four different blood eosinophil cutoffs: $<2 \%, \geq 2 \%$ and $<3 \%$, $\geq 3 \%$ and $<4 \%$, and $\geq 4 \%$. only once, while it appears to vary above and below the $2 \%$ cutoff in up to half of the COPD subjects. ${ }^{16}$ Finally, it may be hypothesized that the Eos cutoff influences the results. However, the $2 \%$ threshold is the most extensively studied at present, ${ }^{2,6}$ and analyses with a $3 \%$ threshold (considering the Eos distribution in this cohort with a Q3 lower limit at 3.4\%) did not change our conclusions. Even the analyses performed with a 4\% threshold did not provide different results.

In our COPD population as in the ECLIPSE cohort, ${ }^{16}$ COPD patients with higher Eos counts ( $\geq 2 \%$ ) had significantly lower SGRQ scores, suggesting less impact of COPD despite similar lung function abnormalities. The reason for this is not fully understood. The higher prevalence of diabetes in patients with lower Eos counts is also difficult to explain. 
One limitation of the study is that blood Eos were available in only slightly less than half of the population included at the time of data extraction. However, patients with and without available blood Eos levels did not differ in terms of clinical and lung function characteristics or outcomes (not shown), suggesting that Eos measurement was missing at random. Another limitation is the unavailability of absolute Eos counts, which were not recorded in this cohort. However, it is unlikely that they would have provided different results given the tight concordance between analyses performed with the $2 \%, 3 \%$, and $4 \%$ cutoffs.

Given the contradictory data from our study and others regarding the association between Eos and exacerbation risk, exploring the potential predictive value of other biomarkers appears necessary. However, results of a combined analysis of the SPIROMICS and COPD gene studies have been disappointing and lead the authors to conclude that, although some blood biomarkers were significantly associated with the occurrence of exacerbations, none was robust between cohorts; in addition, biomarkers added little altogether to the predictive value of clinical features for exacerbations. ${ }^{17}$

\section{Conclusion}

In this COPD cohort, Eos+ patients (regardless the cutoff chosen) exhibited no specific clinical characteristic, especially regarding symptoms, lung function, exacerbations, and, most importantly, prognosis. Health-related quality of life was better only in Eos+ patients. These findings differ from that of several other studies, which may relate to differences in patients' populations and underlines that Eos count may not be a generalizable biomarker to define clinical COPD phenotypes.

\section{Acknowledgments}

This research was funded by Boehringer Ingelheim France and Pfizer France until 2015 and is now funded by Boehringer Ingelheim France.

The abstract of this paper was presented at ERS International Congress 2016 London/United Kingdom; September $3-7,2016$, as an abstract with interim findings. The abstract was published in the European Respiratory Journal.

\section{Disclosure}

Dr Zysman reports grants and personal fees from Boehringer Ingelheim and personal fees from Novartis, Chiesi, AGEvie outside the submitted work. Dr Deslee reports personal fees from Novartis, AstraZeneca, BTG/PneumRx, Chiesi, and Boehringer Ingelheim, outside the submitted work.
Dr Caillaud reports grants and personal fees from Boehringer Ingelheim, personal fees from Novartis, Bayer, and grants from AstraZeneca, ALK-Abello, and Stallergenes, outside the submitted work. Dr Chanez does not report any conflicts of interest. Dr Escamilla reports grants and personal fees from Boehringer Ingelheim, Novartis, personal fees from AstraZeneca, Mundipharma, ALK, and Chiesi, and nonfinancial support from TEVA, outside the submitted work. Dr Court-Fortune reports grants and personal fees from Boehringer Ingelheim and Novartis. Dr Nesme-Meyer reports grants and personal fees from Boehringer Ingelheim. Dr Perez reports personal fees from Boehringer Ingelheim, Novartis, GSK, Chiesi, and Pierre Fabre, outside the submitted work. Dr Paillasseur reports grants from Initiative BPCO Association, during the conduct of the study. Dr Pinet reports grants and personal fees from Boehringer Ingelheim and Novartis. Dr Jebrak reports grants and personal fees from Boerhringer, Novartis, and Pfizer and personal fees from AstraZeneca during the conduct of the study. Dr Roche reports grants and personal fees from Boehringer Ingelheim, Novartis, and Pfizer and personal fees from Teva, GSK, AstraZeneca, Chiesi, Mundipharma, Cipla, Sanofi, Sandoz, Zambon, 3M, and BRAHMS/Thermo Fischer scientific, outside the submitted work. Dr Burgel reports grants and personal fees from Boehringer Ingelheim and personal fees from Aptalis, Astra-Zeneca, Chiesi, GSK, Novartis, Pfizer, Vertex, and Zambon, outside the submitted work.

\section{References}

1. Woodruff PG, Agusti A, Roche N, Singh D, Martinez FJ. Current concepts in targeting chronic obstructive pulmonary disease pharmacotherapy: making progress towards personalised management. Lancet. 2015;385(9979):1789-1798.

2. Hinds DR, DiSantostefano RL, Le HV, Pascoe S. Identification of responders to inhaled corticosteroids in a chronic obstructive pulmonary disease population using cluster analysis. BMJ Open. 2016;6(6) e010099.

3. Pavord ID, Lettis S, Locantore N, et al. Blood eosinophils and inhaled corticosteroid/long-acting beta-2 agonist efficacy in COPD. Thorax. 2016;71(2):118-125

4. Vedel-Krogh S, Nielsen SF, Lange P, Vestbo J, Nordestgaard BG. Blood eosinophils and exacerbations in chronic obstructive pulmonary disease. The Copenhagen General Population Study. Am J Respir Crit Care Med. 2016;193(9):965-974.

5. Siddiqui SH, Guasconi A, Vestbo J, et al. Blood eosinophils: a biomarker of response to extrafine beclomethasone/formoterol in chronic obstructive pulmonary disease. Am J Respir Crit Care Med. 2015;192(4): 523-525.

6. Pascoe S, Locantore N, Dransfield MT, Barnes NC, Pavord ID. Blood eosinophil counts, exacerbations, and response to the addition of inhaled fluticasone furoate to vilanterol in patients with chronic obstructive pulmonary disease: a secondary analysis of data from two parallel randomised controlled trials. Lancet Respir Med. 2015;3(6):435-442.

7. Barnes NC, Sharma R, Lettis S, Calverley PM. Blood eosinophils as a marker of response to inhaled corticosteroids in COPD. Eur Respir J. 2016;47(5):1374-1382. 
8. Bafadhel M, Davies L, Calverley PM, Aaron SD, Brightling CE, Pavord ID. Blood eosinophil guided prednisolone therapy for exacerbations of COPD: a further analysis. Eur Respir J. 2014;44(3):789-791.

9. Bafadhel M, Greening NJ, Harvey-Dunstan TC, et al. Blood eosinophils and outcomes in severe hospitalised exacerbations of COPD. Chest. 2016;150(2):320-328.

10. Wedzicha JA, Banerji D, Chapman KR, et al. Indacaterol-glycopyrronium versus salmeterol-fluticasone for COPD. N Engl J Med. 2016;374(23): 2222-2234.

11. Duman D, Aksoy E, Agca MC, et al. The utility of inflammatory markers to predict readmissions and mortality in COPD cases with or without eosinophilia. Int J Chron Obstruct Pulmon Dis. 2015;10:2469-2478.

12. Burgel PR, Paillasseur JL, Caillaud D, et al. Clinical COPD phenotypes: a novel approach using principal component and cluster analyses. Eur Respir J. 2010;36(3):531-539.

13. Watz H, Tetzlaff K, Wouters EF, et al. Blood eosinophil count and exacerbations in severe chronic obstructive pulmonary disease after withdrawal of inhaled corticosteroids: a post-hoc analysis of the WISDOM trial. Lancet Respir Med. 2016;4(5):390-398.
14. DiSantostefano RL, Hinds D, Van Le H, Barnes NC. Relationship between blood eosinophils and clinical characteristics in a crosssectional study of a US population-based COPD cohort. Respir Med. 2016;112:88-96.

15. Caillaud D, Chanez P, Escamilla R, et al. Asthma-COPD overlap syndrome (acos) versus "pure" COPD: a distinct phenotype? Allergy. 2017; 72(1):137-145.

16. Singh D, Kolsum U, Brightling CE, et al. Eosinophilic inflammation in COPD: prevalence and clinical characteristics. Eur Respir J. 2014; 44(6):1697-1700.

17. Keene JD, Jacobson S, Kechris K, et al; COPDGene and SPIROMICS Investigators. Biomarkers predictive of exacerbations in the SPIROMICS and COPDGene cohorts. Am J Respir Crit Care Med. 2017;195(4): $473-481$.

\section{Publish your work in this journal}

The International Journal of COPD is an international, peer-reviewed journal of therapeutics and pharmacology focusing on concise rapid reporting of clinical studies and reviews in COPD. Special focus is given to the pathophysiological processes underlying the disease, intervention programs, patient focused education, and self management protocols.

\section{Dovepress}

This journal is indexed on PubMed Central, MedLine and CAS. The manuscript management system is completely online and includes a very quick and fair peer-review system, which is all easy to use. Visit http://www.dovepress.com/testimonials.php to read real quotes from published authors. 